\title{
A MIMO H-shape Dielectric Resonator Antenna for 4G Applications
}

\author{
S. Salihah 1, M. H. Jamaluddin*, R. Selvaraju 1, M. N. Hafiz
}

Wireless Communication Center (WCC), Universiti Teknologi Malaysia (UTM), Skudai, Johor Bharu, Malaysia.

\begin{tabular}{|c|c|}
\hline Article Info & ABSTRACT \\
\hline Article history: & In this article, a Multiple-Input-Multiple-Output (MIMO) H-shape Dielectric \\
\hline & Resonator Antenna (DRA) is designed and simulated at $2.6 \mathrm{GHz}$ for $4 \mathrm{G}$ \\
\hline Received Nov 19, 2017 & applications. The proposed structure consists of H-shape DRA $\left(\varepsilon_{\mathrm{r}}=10\right)$ which \\
\hline Revised Jan 28, 2018 & is mounted on FR4 substrate $\left(\varepsilon_{r}=4.6\right)$, and feed by two different feeding \\
\hline Accepted Feb 12, 2018 & $\begin{array}{l}\text { mechanisms. First, microstrip with slot coupling as Port } 1 \text {. Second, coaxial } \\
\text { probe as Port } 2 \text {. The electrical properties of the proposed MIMO H-shape }\end{array}$ \\
\hline Keywords: & $\begin{array}{l}\text { DRA in term of return loss, bandwidth and gain are completely obtained by } \\
\text { using CST Microwave Studio Suite Software. The simulated results }\end{array}$ \\
\hline Dielectric Resonato & demonstrated a return loss more than $20 \mathrm{~dB}$, an impedance bandwidth of 26 \\
\hline Long term evolution & $\%(2.2-2.9 \mathrm{GHz})$, and gain of $6.11 \mathrm{dBi}$ at Port 1 . Then, a return loss more \\
\hline Multiple input Multiple output & $\begin{array}{l}\text { than } 20 \mathrm{~dB} \text {, an impedance bandwidth of } 13 \%(2.2-2.7 \mathrm{GHz}) \text {, and gain of } \\
6.63 \mathrm{dBi} \text { at Port } 2 \text {. Both ports indicated impedance bandwidth more than } 10\end{array}$ \\
\hline Slot coupling & $\begin{array}{l}\% \text {, return loss lower than } 20 \mathrm{~dB} \text {, and gain more than } 10 \mathrm{dBi} \text { at } 2.6 \mathrm{GHz} \text {. The } \\
\text { simulated electrical properties of the proposed design show a good potential } \\
\text { for LTE applications. }\end{array}$ \\
\hline
\end{tabular}

Copyright $@ 2018$ Institute of Advanced Engineering and Science. All rights reserved.

\section{Corresponding Author:}

Mohd Haizal Jamaluddin,

Wireless Communication Center (WCC),

Universiti Teknologi Malaysia (UTM),

Skudai, Johor Bharu, Malaysia.

Email: haizal@utm.my

\section{INTRODUCTION}

Wireless communication nowadays has been part of human life where people can send data information to communicate everywhere and anywhere with the high speed of transmission. Introducing the LTE with high speed of data transmission, data rates, throughput, and spectrum efficiency make user's life easy where they can surf the internet anytime with happily since it become necessary in our life [1] and [2]. This makes the use of devices such as smart phones, laptop and computers become more attractive which required more advanced RF and communication components [3]. In order to fulfill all the needs in wireless communication community, the designers are required to pursue and optimize available RF components in the mobile wireless network.

Multiple-Input-Multiple-Output (MIMO) technology has been developed and used for several times in mobile wireless networks which provide an excellent channel capacity and high data rates. MIMO technology is implemented by utilizing multiple antennas at the input and output side of the communication system to exploit multipath fading to improve channel capacity, data rates, link reliability, and network coverage [4].

In past few years, microstrip technology has been used to develope MIMO antennas for lower frequency applications. For example, a MIMO antenna for Wi-fi applications is presented with two planar inverted-F antennas (PIFAs) [5]. This MIMO ferrite antenna is proposed at $720 \mathrm{MHz}$ which demonstrated a return loss of $16.4 \mathrm{~dB}$. While in [6], a meander line MIMO antenna for mobile LTE handsets is proposed. The return loss of $12 \mathrm{~dB}$ is observed at $800 \mathrm{MHz}$. All the proposed MIMO antenna with microstrip 
technology shows a good electrical performance at desired operating frequency. However, the use of microstrip technology in developing MIMO antenna usually suffer from radiation and metallic loss, especially at higher frequency design.

Then, Dielectric Resonator Antenna (DRA) is introduced to develop MIMO antenna. DRAs have several benefits for implementation in wireless communication system due to their small size, light weight, high radiation efficiency, small conductive loss, and ease of excitation and fabrication [6]. DRAs also have versatility and simplicity in shape [7]-[10] and feeding mechanisms [11]-[16]. A few research works have been reported such as MIMO DRA with dual polarization [14]. The proposed antenna produced return loss more than $15 \mathrm{~dB}$. In [17], a $700 \mathrm{MHz}$ dual-mode MIMO DRA is proposed for LTE base stations. The antenna demonstrated a return loss more than $12 \mathrm{~dB}$ at the operating frequency. In [18], a MIMO Rectangular Dielectric Resonator Antenna (RDRA) for LTE applications is presented. The proposed antenna is excited using coplanar waveguide (CPW) for Port 1 and coaxial probe for Port 2 which demonstrated a return loss more than $20 \mathrm{~dB}$. However, all the proposed MIMO DRA commonly developed by implementing a basic rectangular shape dielectric resonator as the radiation element which is limit the bandwidth performance.

Therefore, a MIMO H-shape dielectric resonator antenna (DRA) is designed and simulated for LTE applications. Ceramic DRA with dielectric constant of 10 and tan loss 0f 0.0019 has been used in this project. Basically, H-shape DR is developed by removing several parts of the Rectangular-shape DR. By doing this, the effective permittivity of the whole DR volume is reduced and consequently increased the impedance bandwidth (BW) of the proposed DRA [17]. In this work, a MIMO H-shape DRA is designed and simulated using CST software with two different feeding mechanisms at Port 1 and Port 2. The obtained simulated results of MIMO H-shape DRA are compared to the simulated results of basic Rectangular-shape DRA for design verifications.

\section{RESEARCH METHOD}

Basically, the H-shape DRA is developed from the basic Rectangular-shape Dielectric Resonator Antenna (RDRA) as can be seen in Figure 1. There are three stages in order to construct H-shape DRA from the basic RDRA. The first stage, a size of Rectangular Dielectric Resonator (RDR) with dimensions of ( $70 \times$ $60 \times 1.6) \mathrm{mm} 3(\mathrm{~L} \times \mathrm{W} \times \mathrm{H})$ is designed and mounted on FR4 substrate as shown in Figure 1 (a). The second stage, a portion of vacuum filled cube with dimensions of a1 x b1 is inserted and removed from the lower side of RDR, which causes empty cube to remain at the lower side of RDR as shown in Figure 1 (b). This makes U-shape DR is formed from the basic RDR. The third stage, a portion of vacuum filled cube with dimensions of $\mathrm{a} 1 \mathrm{x}$ b1 is inserted and removed from the upper side of U-shape DR, which causes two empty cubes to remain at both sides of the basic RDR. This makes H-shape DR is formed from the basic RDR. Note that, the selected values for a good impedance matching and return loss is decided as a $1=4 \mathrm{~mm}$ and $\mathrm{b} 1=12$ $\mathrm{mm}$ after performing parametric studies.

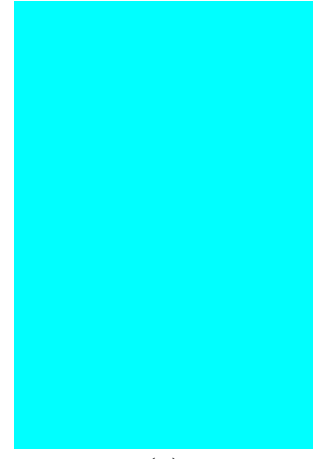

(a)

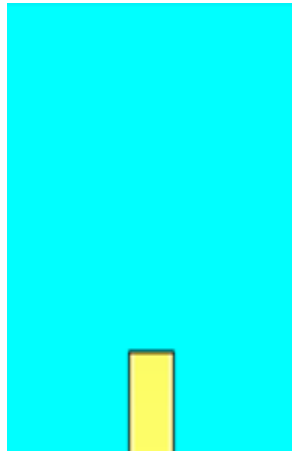

(b)

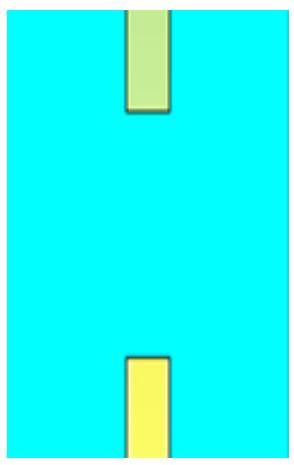

(c)

Figure 1. DRA Cutting Procedures (a) Rectangular Shaped (b) U-Shaped and (c) H-Shaped

Then, two feeder mechanisms are integrated into the H-shape DRA in order to make it behave like a MIMO antenna as shown in Figure 2. First is microstrip line with slot coupling and second is coaxial probe. The length slot of the aperture couple is $\mathrm{Ls}=17 \mathrm{~mm}$ and the width of the aperture couple is $\mathrm{Ws}=2 \mathrm{~mm}$. The radius for all the probe is, $\mathrm{c} 1=1.1 \mathrm{~mm}, \mathrm{c} 2=2.4 \mathrm{~mm}$, and $\mathrm{c} 3=3.0 \mathrm{~mm}$. The height of probe is $\mathrm{H}=18 \mathrm{~mm}$. The input impedance for both feeders is $50 \mathrm{Ohm}$. 


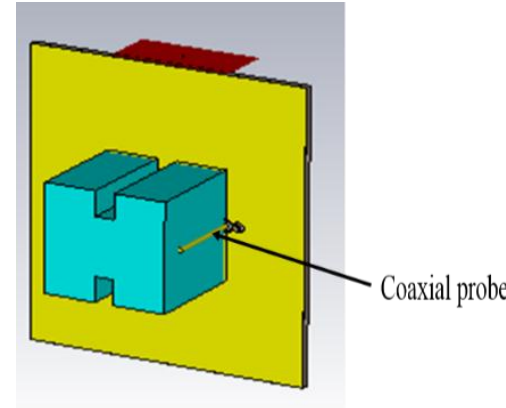

(a)

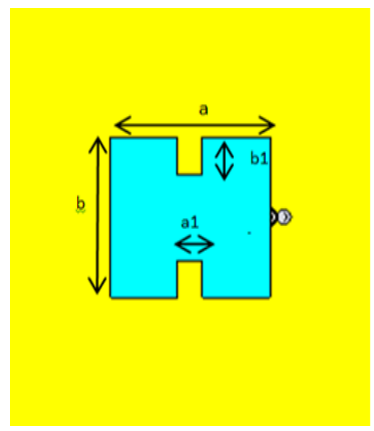

(b)

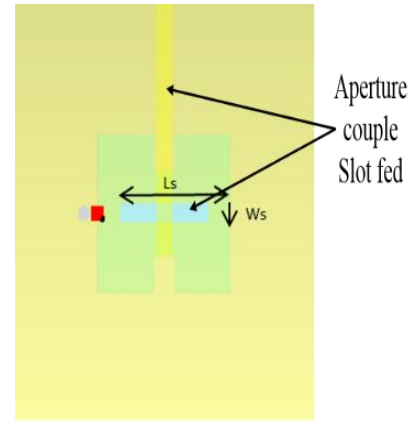

(c)

Figure 2. MIMO H-Shaped DRA Geometry (a) Perspective View (b) Top View (c) Back View.

\section{RESULTS AND ANALYSIS}

In this section, the obtained simulated results from MIMO H-shape DRA is discussed and compared to the simulated results of the basic rectangular-shape DRA. First, the simulated return loss, bandwidth, and resonant frequency of MIMO H-shape DRA is presented in Figure 3. From this simulated results, both ports of the proposed MIMO H-shape DRA shows a slightly different in term of resonance frequency, impedance bandwidth, and return loss. As can be seen, Port 1 is resonated at $2.6 \mathrm{GHz}$ with a return loss of $19 \mathrm{~dB}$ and impedance bandwidth of $26.0 \%$ from $2.2 \mathrm{GHz}$ to $2.8 \mathrm{GHz}$. Meanwhile, Port 2 is resonated at $2.65 \mathrm{GHz}$ with a return loss of $18 \mathrm{~dB}$ and impedance bandwidth of $11.5 \%$ from $2.5 \mathrm{GHz}$ to $2.8 \mathrm{GHz}$. A slight difference is due to the use of different types of feeding mechanism between both ports. However, in this case, Microstrip with slot coupler at Port 1 shows a good feeder mechanism compared to coaxial probe at Port 2 based on the simulated resonant frequency, bandwidth, and return loss performance. Therefore, simulated data of MIMO H-shape DRA at Port 1 is used to compared with simulated data of the basic Rectangular-shape DRA.

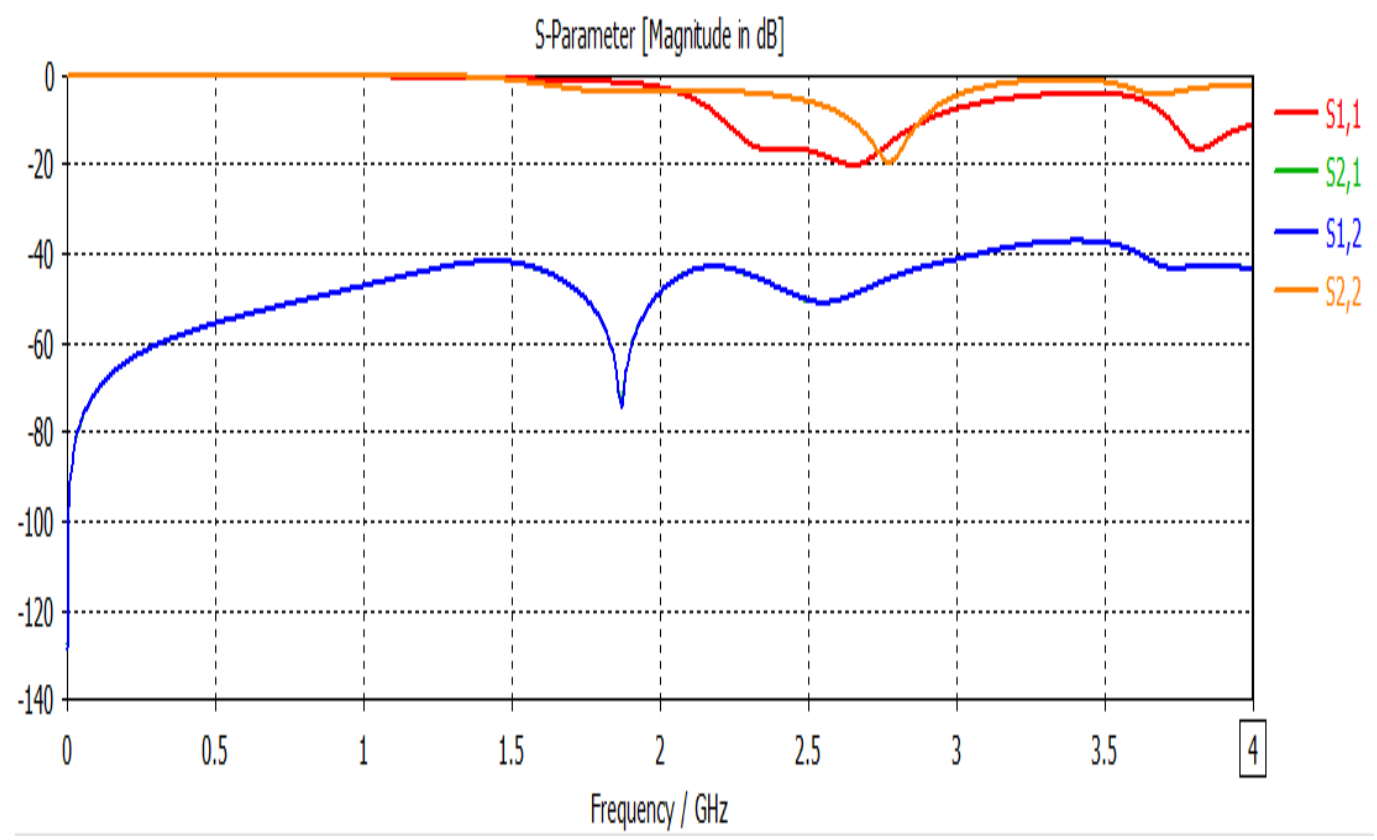

Figure 3. Simulated Return Loss, Bandwidth and Resonant Frequency of MIMO H-Shaped DRA.

Then, a comparison between simulated return loss and impedance bandwidth between the basic rectangular-shape DRA and MIMO H-shape DRA at Port 1 is demonstrated in Figure 4. For the basic rectangular-shape DRA, a return loss of $35 \mathrm{~dB}$ is observed with an impedance bandwidth of $15.4 \%$ from 2.4 $\mathrm{GHz}$ to $2.8 \mathrm{GHz}$ at $2.6 \mathrm{GHz}$. Then, for the MIMO H-shape DRA, a return loss of $19 \mathrm{~dB}$ is observed with an impedance bandwidth of $26.0 \%$ from $2.2 \mathrm{GHz}$ to $2.8 \mathrm{GHz}$ at $2.6 \mathrm{GHz}$ for Port 1 . As can be seen, the 
proposed MIMO H-shape DRA has indicated an improved bandwidth performance of $10.6 \%$ compared to the basic Rectangular-shape DRA. However, the simulated return loss of MIMO H-shape DRA is smaller than simulated return loss of basic rectangular-shape DRA due to the effect from the second feed mechanism at Port 2.

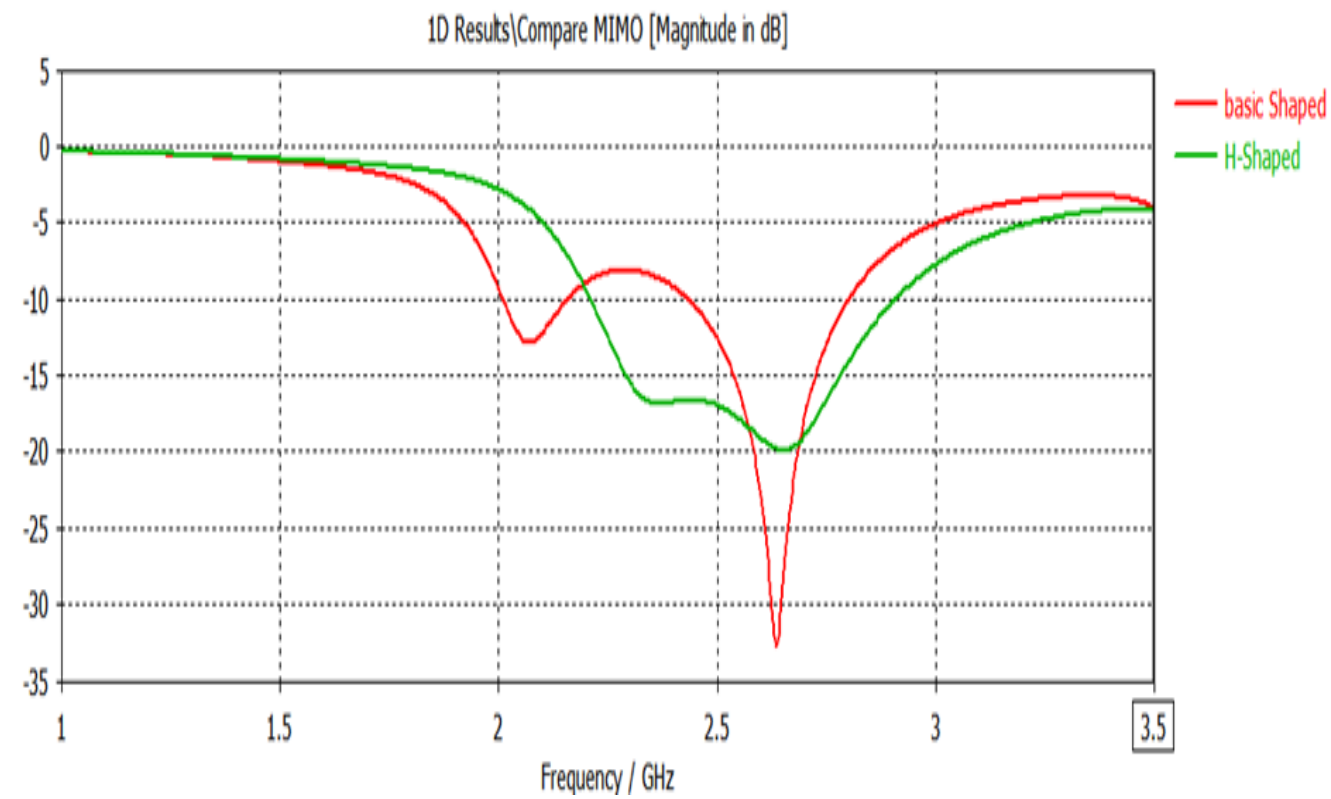

Figure 4. Comparison of Simulated Return Loss and Impedance Bandwidth between Basic Rectangular-Shape DRA and MIMO H-Shape DRA at Port 1.

Finally, the comparison of simulated radiation pattern between the basic rectangular-shape DRA and MIMO H-shape DRA is presented in Figure 5. Simulated radiation patterns for both antennas are indicated almost similar pattern at $2.6 \mathrm{GHz}$. For the simulated E-plane radiation patterns, both antennas show the directional pattern with a gain of $6.08 \mathrm{dBi}$ for MIMO H-shape DRA at Port 1, $6.66 \mathrm{dBi}$ for MIMO H-shape DRA at Port 2, and $6.05 \mathrm{dBi}$ for basic rectangular-shape DRA. Then, for the simulated H-plane radiation patterns, both antennas show almost an omnidirectional pattern at $2.6 \mathrm{GHz}$, which received almost same power at any directions.

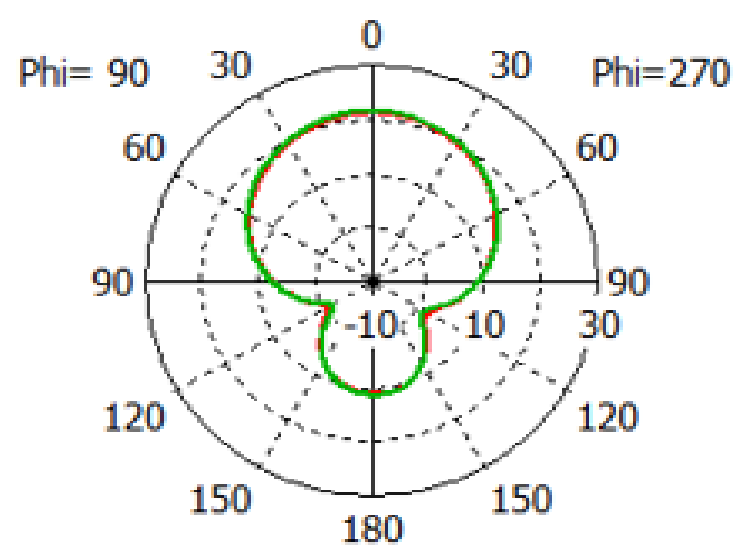

(a)

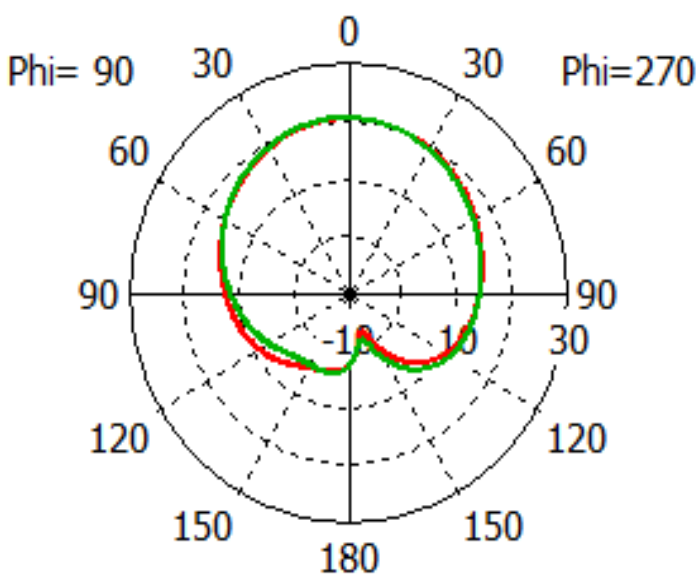

(b)

Figure 5. Comparison of Simulated Radiation Patterns between Basic Rectangular-Shape DRA and MIMO H-Shape DRA at 2.6 GHz (a) E-Field (b) H-Field. 
A MIMO H-shape DRA for $4 \mathrm{G}$ applications is presented in this article. The H-shaped DRA is mounted on FR4 substrate with two different feeding mechanisms to obtain a MIMO characteristics. The simulated antenna has a bidirectional and almost omnidirectional radiation pattern with reasonable electrical properties at the operating frequency of $2.6 \mathrm{GHz}$. The simulated return loss is lower than $10 \mathrm{~dB}$ with an impedance bandwidth of $26 \%(2.22-2.9 \mathrm{GHz})$ at Port 1 and impedance bandwidth of $13 \%(2.2-2.7 \mathrm{GHz})$ at Port 2. Then, the simulated gain has demonstrated a value of $6.08 \mathrm{dBi}$ at Port 1 and $6.66 \mathrm{dBi}$ at Port 2. At the same time, the impedance bandwidth of the MIMO H-shape DRA show improvement of $10.6 \%$ compared to the impedance bandwidth of basic rectangular-shape DRA. These electrical properties show a good potential for LTE applications.

\section{ACKNOWLEDGEMENTS}

This project is sponsored by the Ministry of Education Malaysia and Universiti Teknologi Malaysia under Vot 4J211, Vot 03G33, Vot 4J220, Vot 13H26 and Vot 11H59. The authors would like to thank the staff of the Wireless Communication Centre (WCC) of Universiti Teknologi Malaysia (UTM) for the technical support.

\section{REFERENCES}

[1] J Lee, Y Hong, S Bae, GS Abo, W Seong, G Kim. "Miniature Long-term Evolution (LTE) MIMO Ferrite Antenna". in IEEE Antennas Wireless Propagation Letter. 2011; 10: 603-606.

[2] HS Wong, MT Islam, S Kibria. "Design and Optimization of LTE 1.8 GHz MIMO antenna". in Science World Journal. 2014: 1-10.

[3] J Lu, Z Lin. "Planar Compact LTE/WWAN Monopole Antenna for Tablet Computer Application". in IEEE Antennas Wireless Propagation Letter. 2013; 1: 147-150.

[4] GT Jeong, S Choi, K Lee, WS Kim. "Low-profile Dual-wideband MIMO Antenna with Low ECC for LTE and WiFi Applications". in International Journal Antennas and Propagation. 2014: 1-6.

[5] MS Sharawi, SS Iqbal, YS Faouri. "An $800 \mathrm{MHz} 2 \times 1$ Compact MIMO Antenna System for LTE Handsets". in IEEE Transaction and Antennas Propagagion. 2011; 59: 3128-3131.

[6] H Bae, FJ Harackiewicz, M Park, T Kim, N Kim, D Kim, B Lee. "Compact Mobile Handset MIMO Antenna for LTE 700 MHz Applications". in Microwave Optic and Technology Letter. 2016; 52: 2419-2422.

[7] SF Roslan, MR Kamarudin, M Khalily, MH Jamaluddin. "An MIMO Rectangular Dielectric Resonator Antenna for 4G Applications". in IEEE Antennas Wireless Propagation Letter. 2014; 13: 321-324.

[8] RK Chaudhary, R Kumar, KV Srivastava. "Wideband Ring Dielectric Resonator Antenna with Annular-shaped Microstrip feed". in IEEE Antennas Wireless Propagation Letter. 2013; 12: 595-598.

[9] R Chair, AA Kishk, KF Lee, CE Smith. "Wideband Flipped Staired Pyramid Dielectric Resonator Antennas". in Electronic Letter. 2004; 40: 13-14.

[10] R Selvaraju, MR Kamarudin, M Khalily, J Nasir, MH Jamaluddin. "Dual Band Rectangular Dielectric Resonator Antenna for WLAN Application". in JURNAL TEKNOLOGI. 2016; 78 (6-2): 65-69.

[11] M Abedian, SKA Rahim, M Khalily. "Two-segment Compact Dielectric Resonator Antenna for UWB Application," in IEEE Antennas Wireless Propagation Letter, Vol. 11, pp. 1533-1536, 2012.

[12] EKI Hamad, HA Atallah. "Bandwidth Improvement of Compact High Permittivity RDRA using Parasitic Conducting Strips". In: 6th European Conference on Antennas and Propagation. Prague. 2015: 5-8.

[13] A Buerkle, K Srabandi, H Mosallaei. "Compact Slot and Dielectric Resonator Antenna with Dual-resonance Broadband Characteristics," in IEEE Trans. Antennas Propag. 2005; 53(3): 1020-1027.

[14] TA Denidni, Z Weng. "Hybrid Ultrawideband Dielectric Resonator Antenna and Band-notched Designs". in Microwave Antennas and Propagation. 2011; 5(4): 450-458.

[15] R Selvaraju, MR Kamarudin, M Khalily, MH Jamaluddin, J Nasir. "Dual-Port MIMO Rectangular Dielectric Resonator Antenna for 4G-LTE Application”. in Applied Mechanics and Materials. 2015; 781: 24-27.

[16] R Selvaraju, MR Kamarudin, M Khalily, MH Jamaluddin, J Nasir. "Dual band rectangular dielectric resonator antenna design". in Progress in Electromagnetics Research Symposium. 2014: 2244-2247.

[17] L Zou, D Abbott, C Fumeaux. "Omnidirectional Cylindrical Dielectric Resonator Antenna with Dual Polarization". in IEEE Antennas Wireless Propagation Letter. 2012; 11: 515-518.

[18] B Yan, JT Bernhard. "Design of a MIMO Dielectric Resonator Antenna for LTE Femtocell Base stations". in IEEE Trans. Antennas Propagation. 2012; 60(2): 438-444.

[19] P Rezaei, M Hakkak, K Forooraghi. "Design of Wide-band DRA with a Two-Segment Structure". in Progress In Electromagnetics Researc (PIER). 2006; 6: 111-121. 


\section{BIOGRAPHIES OF AUTHORS}

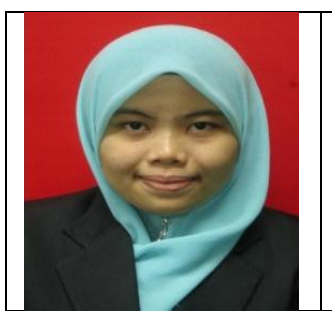

SIT SALIHAH ABD RAHIM was born in Muar, Johor, Malaysia, in 1994. She completed her bachelor's degrees (with honors) in electrical and electronic engineering from the University Technology Malaysia in 2017. Currently she is doing master study in Electonic Engineering (Telecommunication) at University Teknikal Malaysia Melaka. During her studies, she involves with antenna project especially Dielectric Resonator Antenna design.

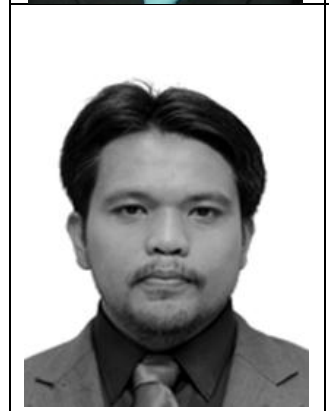

MOHD HAIZAL JAMALUDDIN was born in Selangor, Malaysia, in 1981. He received the bachelor's and master's degrees in electrical engineering from Universiti Teknologi Malaysia, Malaysia, in 2003 and 2006, respectively, and the Ph.D. degree in signal processing and telecommunications from the Université de Rennes 1, France, in 2009 , with a focus on microwave communication systems and specic antennas such as dielectric resonator and reflectarray and dielectric dome antennas. He joined the Department of Electronic Engineering, Faculty of Electrical Engineering, Universiti Teknologi Malaysia, as a Tutor in 2003. He is currently an Associate Professor with the Wireless Communication Centre, Faculty of Electrical Engineering, Universiti Teknologi Malaysia. His research interests include dielectric resonator antennas, printed microstrip antennas, MIMO antennas and DRA reflectarray antenns. He has published more than 80 papers in reputed indexed journals and conference proceedings.

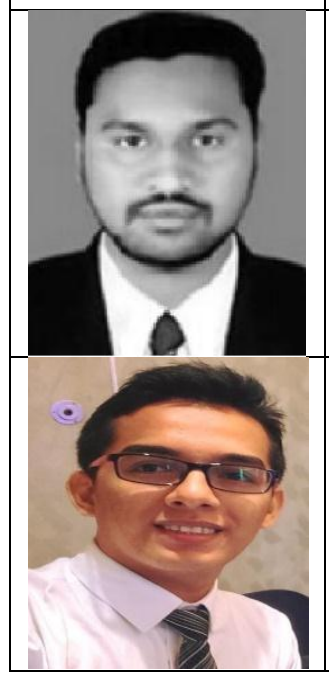

RAGHURAMAN SELVARAJU was born in Gandarvakottai, Tamilnadu, India, in 1989. He received the bachelor's degree in electronics and communication engineering and master's degree in wireless communication systems in 2011 and 2014, respectively from Periyar Maniammai University, India. He is currently a Ph.D. Student and a Researcher with the Wireless Communication Centre, Faculty of Electrical Engineering, Universiti Teknologi Malaysia. His research interests include microstrip patch antennas, dielectric resonator antennas, MIMO antennas, beamforming array antennas, mutual coupling analysis, metamaterials, and split ring resonators.

MUHAMAD HAFIZ was born in Kelantan, Malaysia, in 1991. He received the bachelor's degree in electronics and communication engineering and master's degree by research in year 2015 and 2017, respectively from University Science Malaysia, Malaysia. During his studies, he involves with antenna project especially Substrate Integrated Waveguide (SIW) antennas and Dielectric Resonator Antenna design. 